\title{
BEHAVIORAL SYNDROMES IN THE SAGEBRUSH CRICKET: A PILOT STUDY TO QUANTIFY INDIVIDUAL VARIATION IN MALE CALLING BEHAVIOR
}

\section{J. CHADWICK JOHNSON $\downarrow$ GINA MARIE HUPTON $\downarrow$ ARIZONA STATE UNIVERSITY $\uparrow$ TEMPE}

\section{$\downarrow$ AbSTRACT}

The field of behavioral ecology has recently been reinvigorated by the addition of the notion of behavioral syndromes (a.k.a. animal personality). Behavioral syndromes imply the existence of individual variation in behavioral expression that is consistent across distinct functional contexts (e.g. foraging, mating, anti-predator). The syndromes paradigm suggests that the behavioral phenotype is best viewed as an integrated phenomenon wherein any given behavior can only be fully understood by studying selection pressures in all contexts. Here we report on a pilot study on behavioral syndromes in the Sagebrush cricket (Cyphoderrris strepitans), an acoustic Orthopteran insect that inhabits high altitude sagebrush meadows of Grand Teton National Park. The results of our preliminary analysis suggest very little consistent repeatability in the mating behavior of $C$. strepitans. In addition, we make note of the synergistic collaboration in our group between faculty researchers and graduate, undergraduate and high school research collaborators.

\section{$\uparrow \quad$ INTRODUCTION}

The traditional adaptive paradigm suggests that, over time, natural selection acts to drive phenotypes towards an optimal expression (Figure 1). While the evolutionary power of natural selection is not in question, most evolutionary ecologists work from the underlying assumption that many forces constrain adaptation. For example, available sources of genetic variation limit the types of traits that can be favored by natural selection.
In contrast to this the notion of unbridled plasticity, the field of behavioral ecology has recently been reinvigorated by the notion of behavioral syndromes (i.e. animal personalities; reviewed in Sih et al. 2004, 2010; Figure 2). A behavioral syndrome is individual variation that is consistent across distinct functional contexts. For example, Riechert and colleagues studied behavioral syndromes in the funnel web spider, Agelenopsis aperta. Funnel web spiders demonstrate positive correlations among aggression toward prey, including superfluous killing, boldness toward predators, aggression toward conspecifics, and the size of territory defended. Controlled crosses revealed a genetic basis (probably pleiotropy) to these behavioral correlations (see references in Maupin and Riechert 2001 Riechert and Maupin, 2008). In addition to being correlated at the individual level, these behaviors are also correlated at the population level. Riparian populations of $A$. aperta enjoy six times higher prey availability but

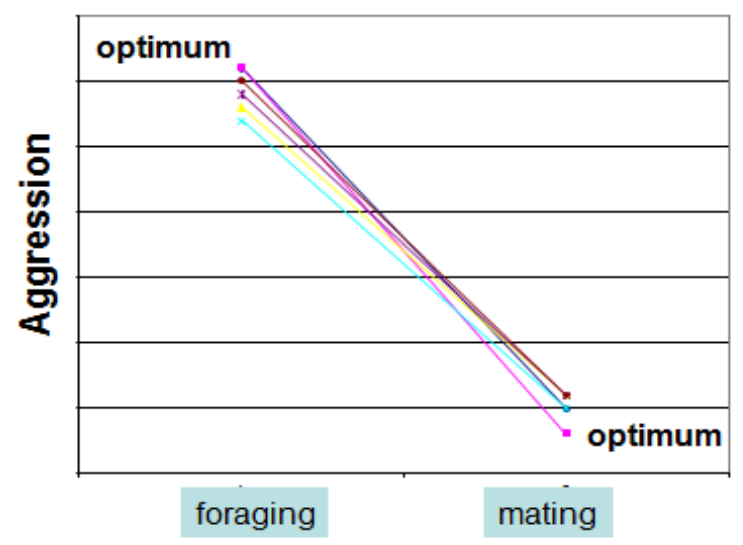

Figure 1. The traditional adaptive paradigm suggesting extensive adaptive plasticity. 


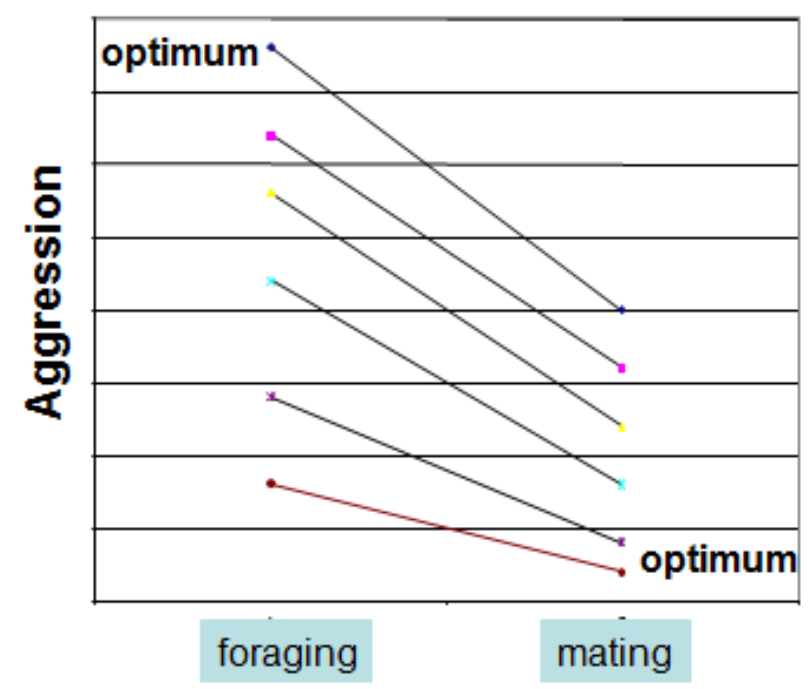

Figure 2. The behavioral syndromes paradigm suggesting extensive individual variation and limits to plasticity.

suffer significantly higher predation risk relative to their counterparts from grassland populations. As one might predict then from a traditional adaptive paradigm, spiders from riparian populations are significantly shyer toward predation risk, less voracious toward prey, less agonistic toward conspecifics, and defend smaller territories than grassland spiders. However, what is most interesting is that within the adaptive modulation going on across populations, we continue to see correlations at the individual level. In other words, although riparian spiders are, on average, shy toward predation risk, some individuals from riparian populations continue to show high levels of boldness toward predators, and this individual variation can be explained by the fact that these bolder individuals are also more voracious toward prey. Conversely, grassland populations are, on average, more voracious toward prey, but some individuals continue to show low voracity toward prey, and this can be explained, at least in part, by the fact that these individuals are also exceedingly shy toward predators (Riechert and Hedrick 1993). This work provides a beautiful illustration of the tug-ofwar occurring between adaptation to one's environment at the population level and potential constraints arising from behavioral correlations occurring at the level of individuals.

More recently, Johnson and Sih (2005, 2007), working with the semiaquatic fishing spider Dolomedes triton, investigated a connection between behavioral syndromes and precopulatory cannibalism by females on courting males. Precopulatory sexual cannibalism can be puzzling from an evolutionary point of view particularly when it results in females not mating enough to fertilize their eggs (Arnqvist and Henriksson 1997). The adaptive foraging hypothesis (Johnson and Sih 2005) explains precopulatory sexual cannibalism by positing that females that had poor foraging success on other prey (e.g., crickets) might be willing to risk the cost of lost reproduction in favor of the benefits of food. Contrary to this hypothesis, Johnson and Sih found that females that most readily attack males are the voracious females that had the highest levels of recent foraging success on other prey. That is, female spiders exhibited positive behavioral correlations between voracity toward heterospecific prey, boldness toward predation, and tendency to attack males. These data are consistent with the hypothesis that precopulatory sexual cannibalism reflects a carryover of voraciousness toward prey, in general, on to voraciousness toward potential mates.

Subsequent studies showed that this carryover is not absolute: if a female grew up experiencing low availability of males, then she is less likely to engage in sexual cannibalism (Johnson and Sih 2005).

Thus, the extent to which animal behavior is driven by adaptive plasticity versus constraint is a pressing question in the current field of behavioral ecology. To address this issue, more studies on more taxa need to follow individuals through their lifetime: 1) documenting the repeatability of an individual's behavioral expression within a context, and 2) looking for the across -context correlations that are the hallmark of a behavioral syndrome. Here we approach the mating behavior of the sagebrush cricket, Cyphoderris strepitans, with the behavioral syndromes approach.

\section{STUDY SYSTEM}

C. strepitans is an acoustic Orthopteran insect from the family Haglidae. Sagebrush crickets emerge soon after snowmelt in high-altitude sagebrush meadows. Several populations residing within and around Grand Teton National Park have received considerable attention (e.g. Sakaluk 1991, Sakaluk and Sneddon 1990, Sakaluk et al. 1987, 1995, 2004).

Of particular interest is the mating system of C. strepitans. Male sagebrush crickets stridulate (call) to attract females for mating. Calling song is produced by a file and scraper mechanism found on opposing edges of the male's calling wings, the tegmina (Figure 3). However, upon mounting a male, females begin to chew on a pair of fleshy hind wings located underneath the tegmina (Figure 3). These 


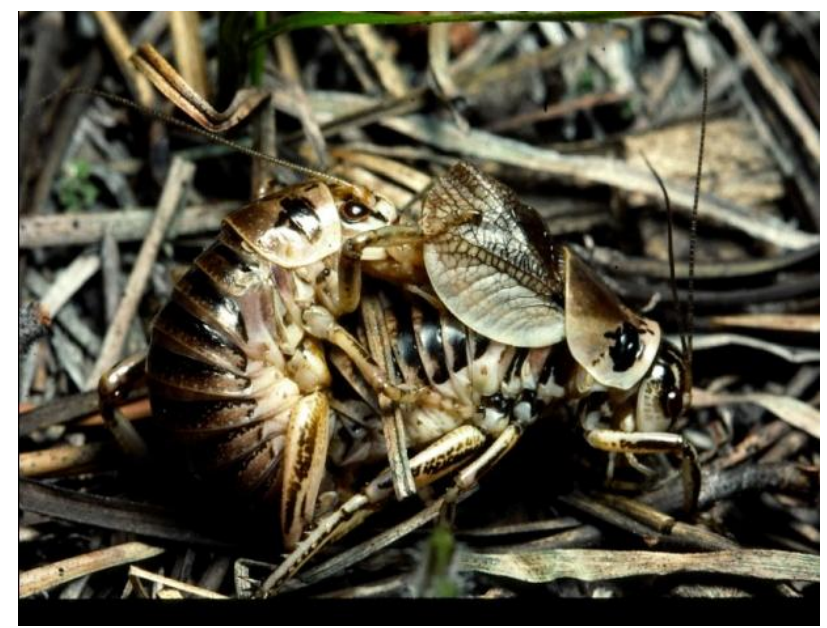

Figure 3. A copulating pair. Wingless females mount the male's dorsum and feed on the male's fleshy hindwings while male's struggle to transfer a spermatophore. (Photo: S. K. Sakaluk)

fleshy hind wings then produce hemolymph which the female consumes while the male is busy transferring an external spermatophore to the female. Thus, the mating system of sagebrush crickets is characterized by a non-lethal form of sexual cannibalism-females consume irreplaceable male body parts, but males are not prevented from mating again in the future (Figure 4).

Sexual cannibalism has been argued to be an ideal target behavior in the study of behavioral syndromes as it so naturally combines the distinct functional contexts of foraging and mating behavior into an integrated context (Johnson, 2001). For example, the fishing spider case study discussed above nicely illustrates a case where sexual cannibalism integrates foraging, mating and antipredator behavior. Here we present preliminary data designed to measure the repeatability of male calling behavior in the field. As per the behavioral syndromes hypothesis we predicted we would find repeatable individual variation (behavioral types) in calling behavior.

\section{STUDY AREA}

We focused study on a small sub-population of Sagebrush crickets from the Lower Dead Man'sbar population (Figure 5). Our study site was bounded to the North by a steep drop from the meadow to the Snake River, to the South by a dirt road, to the East by forest, and to the West by a small hill-below which were more sagebrush bushes. Thus, while this was a reasonably-sized discrete area with an abundance of sagebrush and crickets, the habitat continued to the

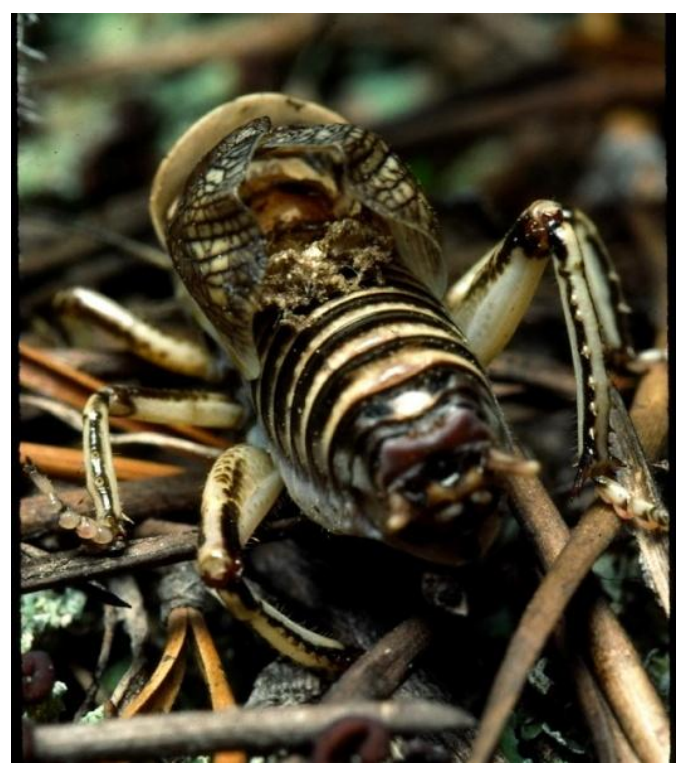

Figure 4. A mated male. Males displaying a dried scab over their hindwings can reliably be scored as mated. (Photo courtesy of Scott K. Sakaluk)

South and West. We broke this area up into 4 quadrants, each approximately $50 \times 100 \mathrm{~m}$.

\section{$\uparrow \quad$ METHODS}

Our 2011 field season ran from June 1 through June 11. Much of our time in Wyoming was limited by rain, which combined with cold temperatures can limit calling behavior for the entire night. Nevertheless, we measured the calling behavior of 18 different males in the field. After this initial field measurement we collected all males and transported them to the laboratory where they were weighed to the nearest milligram and given a unique I.D. tag secured to the pronotum. Marked males were then returned the next day to the base of the bush they were found calling from. On subsequent nights we recorded repeated measures of the calling behavior of these males $(\mathrm{N}=15$ males scored twice; $\mathrm{N}=9$ males scored three times; $\mathrm{N}=6$ males scored 6 times).

\section{$\downarrow \quad$ PRELIMINARY ReSUltS}

We found no significant differences across repeated measures in calling behavior. Figure 6 shows that the number of calling bouts across repeated measures did not vary $\left(\mathrm{F}_{3,15}=0.452\right.$, $\mathrm{p}=0.72$ ). Figure 7 shows that calling duration did not differ across repeated measures $\left(\mathrm{F}_{3,15}=0.937\right.$, 
$\mathrm{p}=0.45)$. Figure 8 shows that average calling bout length did not vary across repeated measures $\left(\mathrm{F}_{3,15}=\right.$ 1.23, $\mathrm{p}=0.33$ ). Thus, across time, we found no evidence that crickets changed their calling behavior.

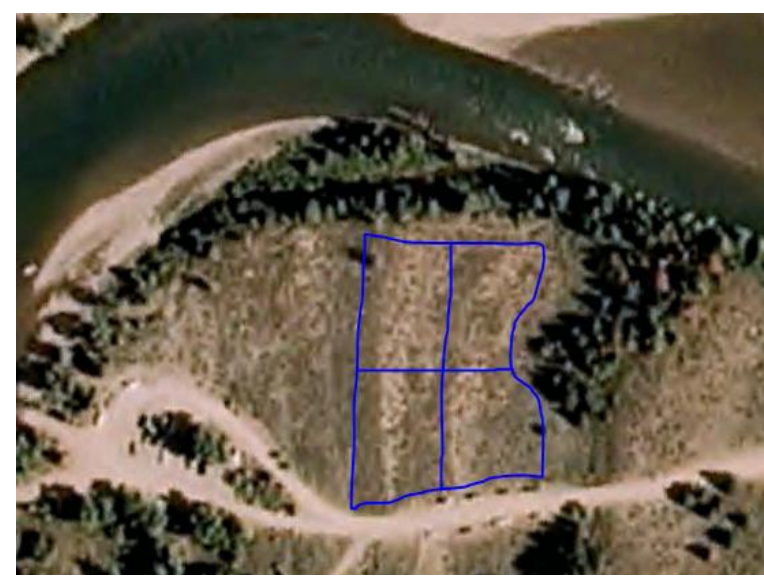

Figure 5. The study location at lower Dead Man's bar divided into 4 quadrats.

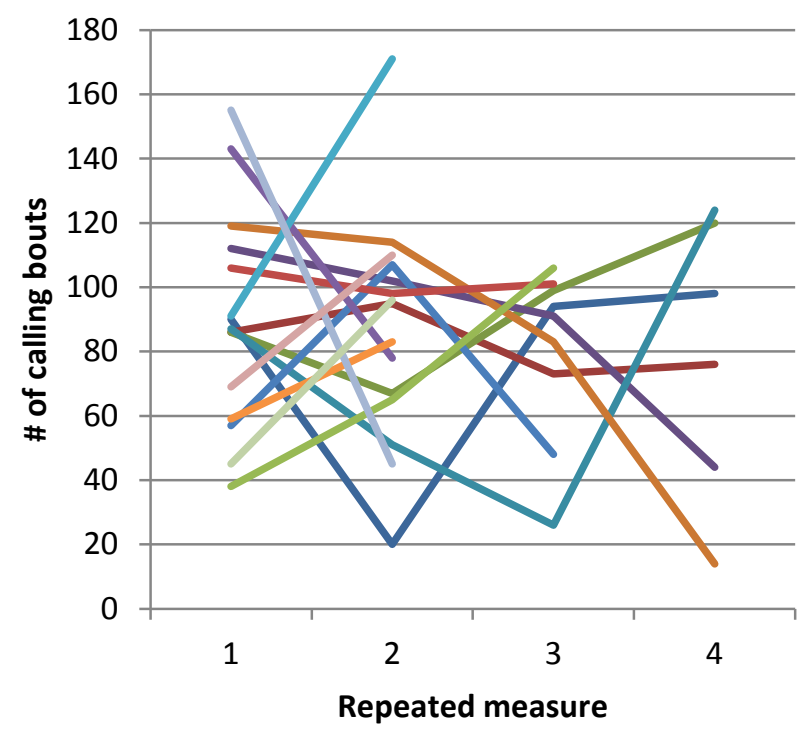

Figure 6. Number of calling bouts did not differ across repeated measures.

Despite the above analysis suggesting that crickets are calling similarly between repeated measures, we found no evidence of consistent individual variation across repeated measures. In other words, we found no evidence of behavioral calling types in the Sagebrush cricket as crickets did not display consistency in number of calling bouts (Intra-class correlation coefficient $=-0.259$, $\mathrm{F}=0.180, \mathrm{p}=0.97$ ), calling duration (Intra-class correlation coefficient $=-0.553, \mathrm{~F}=0.288, \mathrm{p}=0.99$ ), or average bout length (Intra-class correlation coefficient $=-0.078, \mathrm{~F}=0.711, \mathrm{p}=0.63)$. Lastly, a male's calling behavior (bout number and calling duration) was not positively correlated with his foraging behavior (measured in the laboratory as mass after a night of laboratory feeding - mass at collection) as would be predicted by the behavioral syndromes hypothesis. However, we did find a marginal, but significant, trend for males that had longer average bout lengths to also gain more weight in lab feedings $(r=0.410, p=0.045$; see Figure 9).

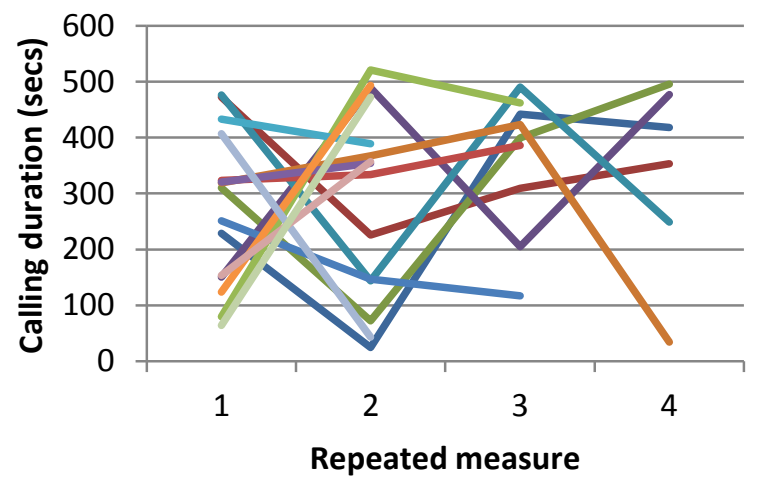

Figure 7. Calling duration did not differ across repeated measures.

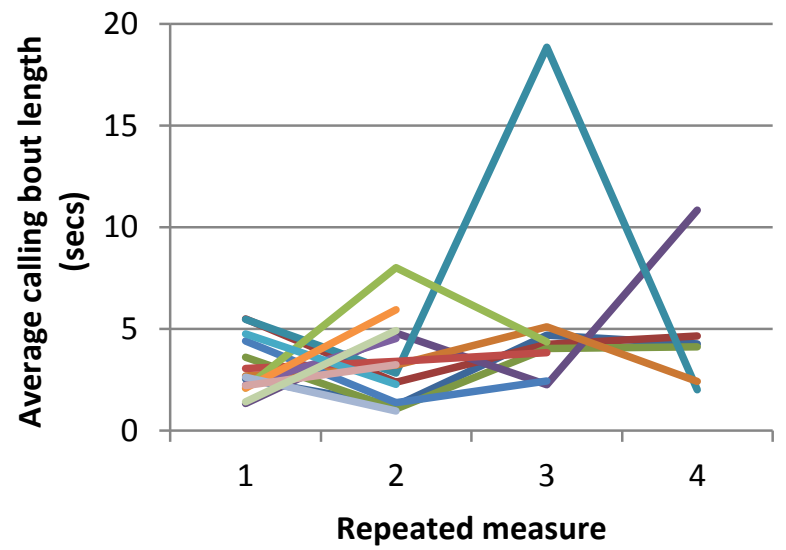

Figure 8. Average calling bout length did not differ across repeated measures.

While our preliminary analyses do not seem to support a behavioral syndromes hypothesis, they are also surprisingly inconsistent with the more traditional adaptive notion that a male's calling behavior should be dependent on his current condition-allowing high-condition males the plasticity to call a great deal. Instead, we found no relationship whatsoever between a male's calling behavior (bout number, average bout length and calling duration) on the night of first capture and his body condition (mass/body length) measured later that night (Pearson correlation, all p>0.05). 


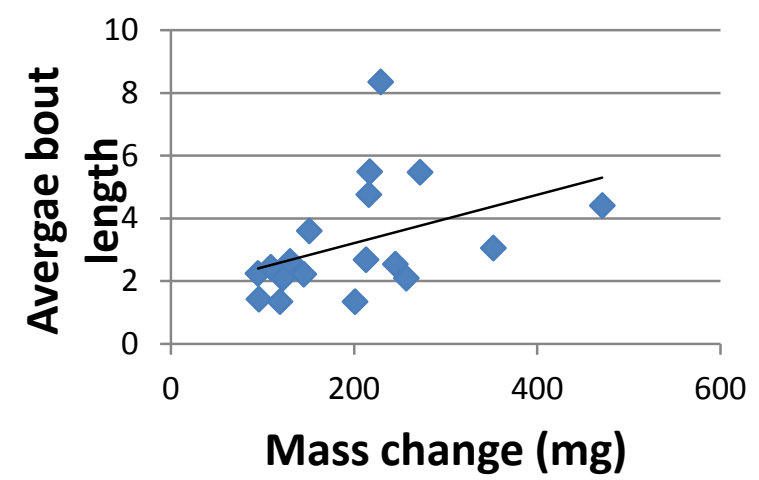

Figure 9. A marginal but significant positive correlation between mass change after a night of lab feeding and average bout length.

\section{$\uparrow \quad$ DISCUSSION}

We were disappointed to find no evidence of a behavioral syndrome, and shocked to find no relationship between male body condition and calling behavior. These results leave us wondering what is, in fact, driving male calling behavior. We do know that male calling is severely compromised after mating behavior (Sakaluk et al., 1987, Sakaluk and Sneddon, 1990). This, however, could not explain the results of this study as we focused our efforts in the first few days of the mating season and each of our males were virgins at their first capture as evidenced by their intact hindwings. One possible confound could be the lack of power in our dataset from the compromised sample size we were able to secure in a brief field season fraught with rain and cold. Indeed, male calling behavior from night to night was very clearly enhanced by warmer temperatures in the absence of precipitation. These abiotic factors, especially early in the breeding season may drown out any smaller effects of behavioral syndromes and/or condition-dependent adaptive plasticity.

One way to remedy this problem would be to collect virgin males and conduct calling assays in a controlled laboratory setting. While this may be worth consideration, it must be noted that calling behavior in ideal lab settings will not allow us to gain an understanding of the behavioral phenotype of Sagebrush crickets experiencing field conditions. One compromise approach would involve the construction of field mesocosms where a sagebrush bush is surrounded by metal flashing to isolate and contain a focal male cricket, and some type of shelter over the bush is constructed. Thus, by removing precipitation, we suggest male calling behavior could be more readily quantified in the field without losing all of the complexities that field measurements include.

Behavioral syndromes remain an exciting area of research, and while our preliminary results do not support this notion, it is worth noting that we have only addressed one behavioral context so farmale calling behavior. It may be that male calling behavior is too heavily influenced by abiotic factors to be predicted by a behavioral syndrome. As suggested above, foraging behavior and anti-predator behavior are also frequent foci of syndromes research. In particular, we were intrigued last Spring at the extent to which the activity of Robins (Turdus migratorus) and the onset of male calling behavior overlapped at dusk. Thus, it is our hope to run preliminary trials this year to see whether Robins do prey upon sagebrush crickets despite the wealth of anti-predator behaviors they employ. Once a realistic anti-predator assay is designed, we could then look for correlations between anti-predator behavior, foraging behavior, and mating behavior.

\section{$\uparrow \quad$ BROADER IMPACTS}

Despite a bit of a disappointing dataset in 2011, we left the station more excited than ever about our future involvement in this system. This is, in large part, due to the outstanding level of interaction we were able to have with Chuck Collis and his team of high school researchers. Chuck's group carried out an impressive mark/recapture study in collaboration with Scott Sakaluk's research group, but at the same time made time to help us with the work detailed above. This collaboration was so successful that Scott, Chuck and our group have teamed up to return this Spring for a more formal collaboration. Scott has successfully secured NSF supplemental funds to help fund this collaboration, and we believe it will be become a model for engaging students across multiple levels in field research.

\section{$\uparrow \quad$ ACKNOWLEDGEMENTS}

We thank Hank Harlow and Celeste Havener for logistical support coordinating our work. Charles Collis generously allowed us to work with his group of high school students from St. Louis, Missouri. Finally, we thank Scott Sakaluk for introducing me to this system and allowing me to join his research efforts. This work is dedicated the memory of Gene and Velma Bass. 


\section{Literature Cited}

Arnqvist G, Henriksson S. 1997: Sexual cannibalism in the fishing spider and a model for the evolution of sexual cannibalism based on genetic constraints. Evolutionary Ecology. 11:255-273.

Johnson JC. 2001: Sexual cannibalism in fishing spiders (Dolomedes triton): an evaluation of two explanations for female aggression towards potential mates. Animal Behaviour, 61:905-914.

Johnson JC. Sih A. 2005: Precopulatory sexual cannibalism in fishing spiders (Dolomedes triton): A role for behavioral syndromes. Behavioral Ecology and Sociobiology, 58:390-396.

Johnson JC, Sih A. 2007: Fear, food, sex and parental care: A syndrome of boldness in the fishing spider, Dolomedes triton. Animal Behaviour, 74:1131- 1138.

Maupin JL, Riechert S. 2001: superfluous killing in spiders: A consequence of adaptation to food-limited environments? Behavioral Ecology. 12:569-576.

Morris GK, Gwynne DT, Klimas DE, Sakaluk SK. 1989. Virgin male mating advantage in a primitive acoustic insect (Orthoptera: Haglidae). Journal of Insect Behavior. 2:173-185.

Riechert SE, Hedrick AV. 1993: A test for correlations among fitness-linked behavioural traits in the spider Agelenopsis aperta (Araneae, Agelinidae). Animal Behaviour. 46:669-675.

Riechert SE, Maupin JL. 1998. Spider effects on prey: tests for superfluous killing in five web-builders. In: Selden PA, Editor. Proceedings of the 17th European Colloquium of Arachnology, Edinburgh 1997. Burnham Arachnological Society. P. $203-210$

Sih A, Bell A, Johnson JC. 2004: Behavioral syndromes: An ecological and evolutionary overview. Trends in Ecology \& Evolution. 19:372-378.

Sih A, Bell A, Johnson JC: Behavioral syndromes. In: Evolutionary Behavioral Ecology. Westneat EF, Fox CW Editors. pp. 516-530. Oxford, UK: Oxford University Press; 2010. p 516530.

Sakaluk SK. 1991. Sex for a song (dinner included). Natural History. 100:66-73.

Sakaluk SK, Snedden WA. 1990. Nightly calling durations of male sagebrush crickets, Cyphoderris strepitans: size, mating and seasonal effects. Oikos. 57:153-160.

Sakaluk SK, Morris GK, Snedden WA. 1987. Mating and its effect on acoustic signalling behavior in a primitive orthopteran, Cyphoderris strepitans (Haglidae): the cost of feeding females. Behavioral Ecology and Sociobiology. 21:173-178.

Sakaluk SK, Snedden WA, Jacobson KA, Eggert AK. 1995. Sexual competition in sagebrush crickets: must males hear calling rivals? Behavioral Ecology. 6:250-257.

Sakaluk SK, Campbell MTH, Clark AP et al. 2004. Hemolymph loss during nuptial feeding constrains male mating success in sagebrush crickets. Behavioral Ecology. 15:845-849. 